\title{
Taraxacum Officinale Alcoholic Extract Augments the Cell- Mediated Immune Response in Anti-Anthrax Vaccinated Sheep
}

\author{
Petru POJAR, Carmen Dana ȘANDRU, Elisabeta PASTOR, Constantin CERBU*, Silvana \\ POPESCU, Sergiu ZĂBLĂU, Aurel VASIU, Diana OLAH, Marina SPÎNU, Ioan Ștefan GROZA \\ Faculty of Veterinary Medicine, University of Agricultural Sciences and Veterinary Medicine, Calea Mănăștur. 3-5, \\ Cluj-Napoca, 400372, Romania \\ * Corresponding author: C. Cerbu e-mail: constantin.cerbu@usamvcluj.ro
}

\section{RESEARCH ARTICLE}

\begin{abstract}
Phytotherapy used various preparations in both human and veterinary medicine over time, due to their increased bioavailability and lower costs. Taraxacum officinale of Compositae family, well-known for its therapeutic effects, abundantly grows on Romanian pastures. The research aimed to investigate its alcoholic extract's effects on cellmediated immunity in anti-anthrax vaccinated, grazing sheep. Local Turcana ewes kept on pasture from spring to fall were sc vaccinated with R1190 attenuated anthrax strain, and blood was sampled before and 14 days after the vaccination. In vitro cell-mediated immunity was monitored employing phagocytosis and blast transformation tests in the presence of $T$. officinale alcoholic extract. The extract increased phagocytosis two weeks after the vaccination $(\mathrm{p}<0.001)$, while the blastogenic response also showed significant variations $(\mathrm{p}<0.05)$ over time. There was a positive effect of $T$. officinale extract on the cellular immunity, suggesting its stress alleviating effects in anti-anthrax vaccinated sheep.
\end{abstract}

Keywords: sheep; anti-anthrax vaccination; stress; T. officinale.

Received: 20 November 2020 Accepted: 07 December 2020 Published: 14 May 2021

DOI:

10.15835/buasvmcn-vm:2020.0045

2021 Authors. The papers published in this journal are licensed under the Creative Commons Attribution-NonCommercialNoDerivatives 4.0 International License

\section{INTRODUCTION}

In the food animal industry, appropriate health is a prerequisite of productivity at optimal levels. Technology must not exert a negative influence on animals welfare and vigor by any of the processes involved (Çokçalışkan et al. 2019). Therapy undertaken in animal communities contributes to protecting against various diseases. Still, the shortage of drugs to control infectious and transmissible diseases in the sector resides in up to $35 \%$ loss in breeding stock (Souto et al. 2012). Thus, vaccination remains one of the most important preventive means, mainly against zoonotic diseases such as anthrax (Dutz and Kohout-Dutz 1981; Schneemann and Manchester 2009). This sporadical, non-contagious, disease of mammals, accidental in humans, is caused by Bacillus anthracis, a ground born pathogen, persistent for a very long period, reaching even 200 years, due to its resistant spores (Dragon and Rennie 1995; De Vos V 2004). Herbivorous animals are exposed during the grazing period, of which sheep and goats show the highest susceptibility and shortest clinical course of the disease. Anthrax represents a threat in all areas of the world where vaccination procedures are not implemented. Vaccination against anthrax, a consolidated preventive procedure, usually leads to immunity for the entire grazing season. Prevention must be considered, especially in endemic areas. Nevertheless, in emergency situations, $20 \%$ of the vaccinated animals remain uncovered (Ezzell and Abshire 1988), and supplementary drawbacks were mentioned (Hahn et al. 2006). Some strains, including the Romanian Stamatin R1190 strain, also cause side effects in some of the vaccinated sheep, such as 
local swelling and pain, or, sometimes, the clinical disease. Thus, immune enhancement is being sought by the use of improved vaccines (Fasanella, Adone, and Hugh-Jones 2014) or immune response amplifiers/herbal enhancers (YurdakokDikmen, Turgut, and Filazi 2018). Nevertheless, before adopting vaccination protocols or therapeutic measures, it is vital to investigate the functional status of various immune effectors involved in protection.

Non-specific and specific immune cell-mediated defense mechanisms are protective barriers at the level of possible pathogens entry points into the susceptible host and responsible for antibody synthesis, respectively. Phagocytosis not only provides immediate defense but by incorporating and processing the aggressors (bacteria, viruses, parasites, fungi) or their fractions, which contributes to activating the specific immune system. This way, a whole chain of reactions is triggered, resulting usually in specific protection for the host. Mechanisms and effectors involved differ fundamentally for innate and acquired sides of the immune response, but cooperation between all those is essential for a complete and entirely protective immunity (Arstila 1996; Chaplin D. D. 2010).

For millennia, plants provided a paragon of active principles to treat various diseases, not only in people but in animals as well (Farnsworth et al. 1985). Traditional medicine relies on ethnobotanical practices in more than $80 \%$ of the world's population, located on the rim of illness, and is the most exposed to emerging and re-emerging diseases in endemic areas (Iqbal et al. 2003; Phondani, Maikhuri, and Kala 2010). Plants were also used to improve the efficacy of conventional therapies (Buldain et al. 2018) or procedures such as vaccination (Tamminen, Emanuelson, and Blanco-Penedo 2018).

Compositae (Asteraceae) family, distributed all over the world, is one of the largest plant families with over 20000 species, including some genera well known for their biological activity (Echinacea, Calendula, Chrysanthemum, Taraxacum, Helianthus, Tagetes, Achillea, Arnica, etc) (Koc et al. 2015; Lakshman, Yeasmin, and Gabriel 2014) and showing a very complex chemical composition, based on the species and extraction method (Soković, Skaltsa, and Ferreira 2019).

Taraxacum officinale of Compositae, native to Eurasia and North America, with proven antioxidant and antiinflammatory activities (Sarı and Keçeci 2019) abundantly grows on Romanian pastures. The research aimed to investigate the effects of an alcoholic Taraxacum officinale extract on cell-mediated immunity in anti-anthrax vaccinated, grazing sheep.

\section{MATERIALS AND METHODS}

Animals and sampling. The research was conducted in a flock of 130 Turcana sheep, of which 127 were lactating ewes, and 3 were rams. The breed is a Romanian one, somewhat primitive, well adapted to local conditions. The age of animals ranged between 2 and 5 years. The animals were kept mainly on the pasture from spring to fall, benefitting of a concentrate supplement daily. Antigen priming was carried out with an anti-anthrax live attenuated vaccine, Stamatin 1190 R strain (INMV Pasteur, Bucharest), administered by s.c. injections, during the fall season. Blood was sampled on heparin (50 $\mathrm{IU} / \mathrm{ml}$ ), from the jugular vein of the animals, two weeks prior and two weeks after the vaccination, and both non-specific and adaptive cell-mediated immunity were monitored by means of in vitro phagocytosis and blast transformation tests in the presence of $T$. officinale alcoholic extract.

Methods. Phagocytic test. Phagocytic cells engulf inert particles such as carbon due to their defensive capacity. An in vitro carbon clearance assay was used to evaluate phagocytic activity in the experimental batches, adapted from the technique described before (Khokhlova et al. 2004). $1.5 \mathrm{ml}$ of venous blood collected on heparin (50 IU/ml) received $6 \mu 1$ of the supernatant fraction of India ink (Pelikan AG D-3000, Hanover, Germany) that had been centrifuged at $3000 \mathrm{~g}$ for $30 \mathrm{~min}$. After mixing, each sample was divided into 3 equal aliquots: a) untreated control, b) treated with $70^{\circ}$ alcohol, 1.5 microliters/tube, and c) treated with a Taraxacum officinale (1.5 microliters/tube) alcoholic extract, respectively, which were incubated at $37^{\circ} \mathrm{C}$ for 15 and $30 \mathrm{~min}$ each. Volumes of $150 \mu \mathrm{l}$ of each blood and India ink mixture from each aliquot were added to $2 \mathrm{ml}$ saline following incubation. These diluted samples were centrifuged at $50 \mathrm{~g}$ for $4 \mathrm{~min}$, and the supernatant was read spectrophotometrically at $535 \mathrm{~nm}$, with the saline taken as background. There was a decrease in absorbency with time as carbon was phagocytosed. Optical density readings were converted to a log2 scale and the phagocytic index was taken as the negative of the slope of the regression of optical density $(\log 2)$ on time (h).

Blast transformation test. The blast transformation capacity of leukocytes was tested on whole blood cultures by use of RPMI 1640 (Sigma-Aldrich) culture medium, with 5\% fetal calf serum (FCS)(Sigma-Aldrich). The blood samples were diluted 1:4 with the medium, distributed in 96 well plates in $0.2 \mathrm{ml}$ aliquots. PHA M and LPS (Sigma-Aldrich) (1 $\mu 1 /$ well) were used as a standard mitogen. Alcohol $\left(70^{\circ}, 1.5 \mu \mathrm{l} /\right.$ well $)$ served as the control for Taraxacum officinale alcoholic extract treated variants $\left(1.5 \mu \mathrm{l} /\right.$ well). All variants were performed in duplicate. The plates were incubated at $37^{\circ} \mathrm{C}$ in a $5 \% \mathrm{CO} 2$ atmosphere for 63 hours. The cell growth was estimated by measuring the glucose residue in a colorimetric orto-toluidine test (ICCF, Bucharest) and spectrophotometrical (SUMAL PE2, Karl Zeiss, Jena) measurement $(\lambda=610 \cdot \mathrm{nm}, \mathrm{d}=0.5 \cdot \mathrm{cm}) \mathrm{of}$ the results. Blast transformation indices were calculated as percentages of the consumption versus the initial glucose concentration of the RPMI 1640 medium.

The data were statistically interpreted, by calculating mean values and standard deviations as well as the statistical significance of the differences by use of Student's t-test. 


\section{RESULTS AND DISCUSSIONS}

A continuously growing pool of literature stands for the ever-increasing importance of traditional knowledge in healing with the help of plants, which provided the foundation and continuous support to sustainable development in small communities (Wanzala et al. 2005). Medicinal plants with cholagogic/choleretic properties included chamomile (Chamomilla recutita), elecampain (Inula helenium), dandelion (Taraxacum officinale), St. John's wort (Hypericum perforatum), Artemisia sp, yarrow (Achillea millefolium), rosemary (Rosmarinus officinalis), chelidonium (Chelidonium majus). Essential oils of liquorice, coriander, turmeric, black pepper, red chili, cumin, onion, peppermint also have choleretic properties (Yurdakok-Dikmen, Turgut, and Filazi 2018). Phytotherapy also included various preparations used as bactericidal (Cerioli et al. 2018), antiviral (Kalvatchev, Walder, and Garzaro 1997), immune-stimulating (Bauer 2002), anti-inflammatory, antiparasitic, neurotropic (Attele, Wu, and Yuan 1999), cardio-angiotropic, pneumotropic agents along time (Bullitta, Piluzza, and Viegi 2007; Eshetu et al. 2015), due to increased bioavailability, easy access and lower cost of plant preparations (Raman 2017).

Integration of ethno-veterinary practices into official health care systems still needs scientific support (Wanzala et al. 2005). As prerequisites to improve the results and reproducibility of phytotherapy, the upgrade of clinical trials and real estimates of cost/benefit ratio was also some of the concerns expressed by specialists (Blanco-Penedo et al. 2018).

The in vitro use of the alcoholic T. officinale extract highly significantly $(\mathrm{p}<0.001)$ increased the phagocytosis two weeks after the vaccination (from -0.00267 to 0.022903 units), while the specific cell-mediated response also showed significant variations $(\mathrm{p}<0.05)$ over the tested period (from $36.01 \pm 17.4$ to $55.17 \pm 9.30 \%$ ).

The cells involved in the immediate immune response, those with undifferentiated activity against all aggressors, bacteria, viruses, or fungi, intervene through accumulation in large numbers at the site of aggression as well as by activating the functions they perform, especially phagocytosis. Nevertheless, its intervention in vaccinated animals, while protecting against disease is unclear (Tchalla et al. 2020). Whole blood phagocytes have the ability to ingest not only bacteria but also inert particles (carbon, silicon, etc.). The reduction in the number of carbon particles in a mixture of whole blood and Chinese ink, evaluated spectrophotometrically, provides clues to the functional capacity of circulating phagocytes. In vitro testing of the functional potential of in vitro phagocytes offers information about their ability to recognize and subsequently embed "non-self" particles, not only inert but also biotic (microbial aggressors).

By monitoring the ability to absorb inert carbon particles in vitro, it was noticed that the level at which phagocytes were stimulated differed both by the time of harvest and by the in vitro treatment applied. The immune-stimulating effect exerted by plant extracts on the mechanisms of in vitro phagocytosis would contribute to better uptake and presentation of vaccine antigens, augmenting antibody production. The study of the extent to which this treatment increased phagocytosis would therefore provide data for the assessment of the possible adjuvant value of these types of compounds.

Literature data mention the positive influence of natural feed additives such as freshwater algae (Chlorella vulgaris) on phagocytosis and lymphoid tissue development (Kwak et al. 2012). Significant effects are found in humans after the administration of Echinacea extract, amplifying phagocytic activity in the infused rat liver (Roesler et al. 1991).

The level of phagocytosis in the control variant was decreased subsequent to two weeks after the vaccination. The alcoholic dandelion extract used in vitro had a weak stimulating effect on phagocytosis when compared to controls, notable results being recorded only after 2 weeks, for the first measurement period of $15 \mathrm{~min}$, after which it decreased (Table 1).

Table 1. Phagocytosis during the experiment (units)

\begin{tabular}{ccccccc}
\hline & \multicolumn{2}{c}{ Control } & \multicolumn{2}{c}{ Alcohol } & \multicolumn{2}{c}{ Taraxacum officinale } \\
\cline { 2 - 7 } Sampling & $\operatorname{In} 0-\operatorname{In} 15 / 15$ & $\operatorname{In} 15-\operatorname{In} 30 / 15$ & $\operatorname{In} 0-\operatorname{In} 15 / 15$ & $\operatorname{In} 15-\operatorname{In} 30 / 15$ & $\operatorname{In} 0-\operatorname{In} 15 / 15$ & $\operatorname{In} 15-\operatorname{In} 30 / 15$ \\
\hline I & $0.00915 \pm 0.0174$ & $-1.18162 \pm 0.7591$ & $0.001049 \pm 0.0071$ & $0.000213 \pm 0.0063$ & $0.001766 \pm 0.0144$ & $-0.00193 \pm 0.0149$ \\
\hline II & $-0.00321 \pm 0.0104$ & $0.003313 \pm 0.0239$ & $0.007885 \pm 0.0288$ & $-0.00773 \pm 0.0287$ & $0.003077 \pm 0.0151$ & $-0.00267 \pm 0.0081$ \\
\hline
\end{tabular}

The plant extracts used in vitro have different immunomodulatory effects depending on the time at which the blood was collected.

The blastogenesis of mononuclear cells can be monitored by the in vitro blast transformation test (Lacetera and Ronchi 2004). This technique allows the final calculation of the blast index, a parameter that indicates the stimulation or inhibition of cell growth. The in vitro supplementation of cultures with classical mitogens allowed an estimate of the virtual response to microbial aggression of mononuclear and B lymphocytes.

Table 2. Blast transformation indices in treated cultures ( \%, IInd sampling)

\begin{tabular}{lll}
\hline Experimental variant & Sampling I & Sampling II \\
\hline Control culture & $18.77 \pm 27.96$ & $35.70 \pm 8.71$ \\
\hline LPS & $22.22 \pm 28.70$ & $38.61 \pm 7.12$ \\
\hline PHA & $23.45 \pm 23.92$ & $37.81 \pm 8.40$ \\
\hline Alcohol & $29.34 \pm 23.21$ & $43.95 \pm 10.20$ \\
\hline Taraxacum officinale & $23.58 \pm 24.29$ & $37.58 \pm 9.77$ \\
\hline
\end{tabular}


All values obtained in the blast transformation test were higher after 14 days post-vaccination. When compared to the pre-vaccination results, the latter suggested that the vaccination-induced very low growth, indicating the stress induced by both vaccination and handling, the animals were subjected to.

Although the solvent control induced the highest effect, the level of stimulation induced by the alcoholic dandelion extract was very promising, similar to that of PHA M, both at the initial sampling and significantly higher at the second sampling $(\mathrm{p}<0.05)$. These values were increased when compared to the untreated controls at both readings.

Stimulation indices showed very clearly that animals exposed to dandelion on the pastures during their grazing period of more than 6 months, depending on the climate, could have improved both non-specific and specific immune responses. These could prove efficient not only versus vaccine antigens administered to the animals but also in providing them protection against other aggressors. These data are consistent with some similar citations in the literature regarding the potentiating effects of some other plant extracts used as alcoholic extracts to improve immunity over time (Farnsworth et al. 1985; Iqbal et al. 2003; Khokhlova et al. 2004; Roesler et al. 1991; Yurdakok-Dikmen, Turgut, and Filazi 2018).

\section{CONCLUSIONS}

The results of the present experiment supported the positive effect of $\mathrm{T}$. officinale active principles on the innate and adaptive cell-mediated immunity, indicating the potential uses as immune enhancer/adjuvant in alleviating the stressful effects of anti-anthrax vaccination in sheep.

Author Contributions: M.S. and I.S.G. conceived and designed the analysis; S.Z, A.V. and D.O. Collected the data; C.C. Contributed data or analysis tools; P.P. and S.P. Performed the analysis; P.P. and MS wrote the original draft.

Funding Source: This research did not receive any specific grant from funding agencies in the public, commercial, or notfor-profit sectors.

\section{Acknowledgments}

This research did not receive any specific grant from funding agencies in the public, commercial, or not-for-profit sectors.

\section{Conflicts of Interest}

The authors declare that they do not have any conflict of interest

\section{REFERENCES}

1. Arstila, T P. 1996. "T Cell Subsets and the Activation of Gamma Delta T Cells." Current topics in microbiology and immunology 212: 71-77.

2. Attele, Anoja S, Ji An Wu, and Chun Su Yuan. 1999. "Ginseng Pharmacology: Multiple Constituents and Multiple Actions." Biochemical Pharmacology 58(11): 1685-93.

3. Bauer, R. 2002. "[New knowledge regarding the effect and effectiveness of Echinacea purpurea extracts]." Wiener medizinische Wochenschrift (1946) 152(15-16): 407-11.

4. Blanco-Penedo, Isabel et al. 2018. "Priorities and Future Actions for an Effective Use of Phytotherapy in LivestockOutputs from an Expert Workshop." Frontiers in Veterinary Science 4(JAN): 1-7.

5. Buldain, Daniel et al. 2018. "Combination of Cloxacillin and Essential Oil of Melaleuca Armillaris as an Alternative against Staphylococcus Aureus.” Frontiers in Veterinary Science 5(AUG): 1-8.

6. Bullitta, S., G. Piluzza, and L. Viegi. 2007. "Plant Resources Used for Traditional Ethnoveterinary Phytotherapy in Sardinia (Italy)." Genetic Resources and Crop Evolution 54(7): 1447-64.

7. Cerioli, María F., Melina V. Moliva, Laura N. Cariddi, and Elina B. Reinoso. 2018. "Effect of the Essential Oil of Minthostachys Verticillata (Griseb.) Epling and Limonene on Biofilm Production in Pathogens Causing Bovine Mastitis." Frontiers in Veterinary Science 5(JUL): 1-8.

8. Chaplin D. D. 2010. "Overview of the Immune Response.” Journal of Allergy and Clinical Immunology 125(2): S345.

9. Çokçalışkan, Can et al. 2019. "Effect of Simultaneous Administration of Foot-and-Mouth Disease (FMD) and Anthrax Vaccines on Antibody Response to FMD in Sheep." Clinical and Experimental Vaccine Research 8(2): 103-9.

10. Dragon, D. C., and R. P. Rennie. 1995. "The Ecology of Anthrax Spores: Tough but Not Invincible." The Canadian veterinary journal. La revue vétérinaire canadienne 36(5): 295-301.

11. Dutz, W, and E Kohout-Dutz. 1981. “Anthrax.” International journal of dermatology 20(3): 203-6.

12. Eshetu, Gebremedhin Romha, Tewedros Ayalew Dejene, Lidet Befkadu Telila, and Daniel Fekadu Bekele. 2015. "Ethnoveterinary Medicinal Plants: Preparation and Application Methods by Traditional Healers in Selected Districts of Southern Ethiopia." Veterinary World 8(5): 674-84. 
13. Ezzell, J. W., and T. G. Abshire. 1988. "Immunological Analysis of Cell-Associated Antigens of Bacillus Anthracis." Infection and Immunity 56(2): 349-56.

14. Farnsworth, N. R. et al. 1985. "Medicinal Plants in Therapy." Bulletin of the World Health Organization 63(6): 96581.

15. Fasanella, Antonio, Rosanna Adone, and Martin Hugh-Jones. 2014. "Classification and Management of Animal Anthrax Outbreaks Based on the Source of Infection." Annali dell'Istituto superiore di sanita 50(2): 192-95.

16. Hahn, Ulrike K., Michaela Aichler, Reinhard Boehm, and Wolfgang Beyer. 2006. "Comparison of the Immunological Memory after DNA Vaccination and Protein Vaccination against Anthrax in Sheep." Vaccine 24(21): $4595-97$.

17. Iqbal, $Z$ et al. 2003. "Herbal Dewormers in Livestock-a Traditional Therapy." Int J Agr Biol 5(2): 199-206.

18. Kalvatchev, Z, R Walder, and D Garzaro. 1997. "Anti-HIV Activity of Extracts from Calendula Officinalis Flowers." Biomedicine \& Pharmacotherapy 51(4): 176-80.

19. Khokhlova, Irina S., Marina Spinu, Boris R. Krasnov, and A. Allan Degen. 2004. "Immune Response to Fleas in a Wild Desert Rodent: Effect of Parasite Species, Parasite Burden, Sex of Host and Host Parasitological Experience." Journal of Experimental Biology 207(16): 2725-33.

20. Koc, Suheda et al. 2015. "The Potential Medicinal Value of Plants from Asteraceae Family with Antioxidant Defense Enzymes as Biological Targets." Pharmaceutical Biology 53(5): 746-51.

21. Kwak, Jung Hyun et al. 2012. "Beneficial Immunostimulatory Effect of Short-Term Chlorella Supplementation: Enhancement of Natural Killer Cell Activity and Early Inflammatory Response (Randomized, Double-Blinded, Placebo-Controlled Trial)." Nutrition Journal 11(1): 1-8.

22. Lacetera, Nicola, and Bruno Ronchi. 2004. "Evaluation of Antibody Response and Nonspecific Lymphocyte Blastogenesis Following Inoculation of a Live Attenuated Bluetongue Virus Vaccine in Goats." American Journal of Veterinary Research 65(10): 1331-34.

23. Lakshman, H. C., Tanzima Yeasmin, and K. P. Gabriel. 2014. "Herbs of Asteraceae and Their Ethano - Medicinal Uses in Dermatological Problems.” Journal of Bio-Science 22(1756): 127-29.

24. Phondani, P. C., R. K. Maikhuri, and C. P. Kala. 2010. "Ethnoveterinary Uses of Medicinal Plants among Traditional Herbal Healers in Alaknanda Catchment of Uttarakhand, India." African Journal of Traditional, Complementary and Alternative Medicines 7(3): 195-206.

25. Raman, Ram Prakash. 2017. "Applicability, Feasibility and Efficacy of Phytotherapy in Aquatic Animal Health Management." American Journal of Plant Sciences 08(02): 257-87.

26. Roesler, J et al. 1991. "Application of Purified Polysaccharides from Cell Cultures of the Plant Echinacea Purpurea to Test Subjects Mediates Activation of the Phagocyte System." International journal of immunopharmacology 13(7): 931-41.

27. Sar1, Aynur, and Zeynep Keçeci. 2019. "Phytochemical Investigations on Chemical Constituents of Taraxacum Bessarabicum (Hornem.) Hand.-Mazz. Subsp. Bessarabicum (Hornem.) Hand.-Mazz." Iranian Journal of Pharmaceutical Research 18(1): 400-405.

28. Schneemann, Anette, and Marianne Manchester. 2009. "Anti-Toxin Antibodies in Prophylaxis and Treatment of Inhalation Anthrax." Future microbiology 4(1): 35-43.

29. Soković, Marina, Helen Skaltsa, and Isabel C.F.R. Ferreira. 2019. "Editorial: Bioactive Phytochemicals in Asteraceae: Structure, Function, and Biological Activity." Frontiers in Plant Science 10(November): 1-2.

30. Souto, WEDSON M.S. et al. 2012. "Animal-Based Medicines Used in Ethnoveterinary Practices in the Semi-Arid Region of Northeastern Brazil." Anais da Academia Brasileira de Ciencias 84(3): 669-78.

31. Tamminen, Lena Mari, Ulf Emanuelson, and Isabel Blanco-Penedo. 2018. "Systematic Review of Phytotherapeutic Treatments for Different Farm Animals under European Conditions." Frontiers in Veterinary Science 5(JUN): 1-11.

32. Tchalla, Essi Y.I., Manmeet Bhalla, Elizabeth A. Wohlfert, and Elsa N.Bou Ghanem. 2020. "Neutrophils Are Required during Immunization with the Pneumococcal Conjugate Vaccine for Protective Antibody Responses and Host Defense against Infection.” Journal of Infectious Diseases 222(8): 1363-70.

33. De Vos V, Turnbull PC. 2004. Cape Town: Oxford University Press Southern Africa Anthrax. In: Coetzer JA, Thomson GR, Tustin RC, Editors. Infectious Diseases of Livestock, with Special Reference to Southern Africa. 2nd ed. Vo. Springer.

34. Wanzala, W. et al. 2005. "Ethnoveterinary Medicine: A Critical Review of Its Evolution, Perception, Understanding and the Way Forward." Livestock Research for Rural Development 17(11).

35. Yurdakok-Dikmen, Begum, Yagmur Turgut, and Ayhan Filazi. 2018. "Herbal Bioenhancers in Veterinary Phytomedicine." Frontiers in Veterinary Science 5(OCT): 1-8. 